\title{
El amor, el enamoramiento $y$ el cuerpo: líneas de reflexión sobre el amor romántico en la música latinoamericana (salsa) y la fotografía
}

Carlos Vargas Loáiciga Maestría Estudios Latinoamericanos

Universidad Nacional, Costa Rica

Resumen

El amor es el resultado de una conducta social basada en las tradiciones y la herencia. El amor para el hombre y para la mujer suele ser diferente. Sin embargo, el amor es la más importante experiencia en la vida humana. El tema de este artículo es el amor de pareja en la canción romántica y en las imágenes fotográficas.

Palabras claves: amor, fotografías, pareja, canción de amor

\begin{abstract}
Love is the result of social behavior based upon traditions and inheritance. The idea of love es in general different for man and for woman. However, love is still one of the most important experiences in human life. The subject of this article is related to couple love in romantic songs and in photographic images.
\end{abstract}

Key words: love, pictures, couple, love song 


\section{Introducción}

Una de las acciones más importantes dentro de la vida humana es amar. Si bien es cierto, existen varias formas de amar, el amor romántico es uno de los más importantes dentro de las experiencias personales. Pero, ¿cuáles son los procesos sociales que influyen dentro del imaginario social de las personas para obtener el resultado de lo que es amar? ¿Existen diferencias en el amar de los hombres y las mujeres? Estas son algunas de las preguntas centrales que se pueden desarrollar sobre el amor, el enamoramiento y el cuerpo, que desprenderán líneas de reflexión basadas en la idea del amor, presentes en la música latinoamericana (salsa) y la fotografía.

Todas las personas lo vivimos, lo sentimos, lo expresamos. El amor, desde un enfoque social, es una de las acciones más relevantes dentro de la vida de las personas. Hay diversos tipos de amor, es decir, no hay una sola forma de amar, lo cual implica que no hay un amor determinista que opaque todas las diversidades que se expresan dentro del amor. Sin embargo, sea cual sea el tipo de amor - amor de madre/padre a sus hijos(as) y viceversa, amor hacia las mascotas, amor hacia lo material - en este caso el énfasis será el amor de pareja. Aclaro que este ensayo está enfocado en las parejas heterosexuales. Esto no representa ninguna forma de discriminación hacia otras identidades sexuales o tipos de amor, sino que, como persona heterosexual, considero muy irresponsable acercarme a las formas de amar de la diversidad de parejas, sin haberme acercado a la comprensión de mi propia expresión de este sentimiento. Por lo tanto, el amor de pareja representado por una mujer y un hombre será el enmarque reflexivo de este artículo.

Lo anterior deja claro que mi interés parte desde la experiencia propia, en la que he amado y me han amado. Sin embargo, la forma de expresar ese amor en ambos sentidos (de mí hacia mi pareja y viceversa), puede ser de manera más o menos intensa, más o menos expresiva, o bien, más o menos visible para las demás personas. Esto surge no sólo a partir de mi propia experiencia, sino de la observación que he hecho de otras personas: amigos, familiares, o desconocidos, acentuada en los últimos años por las redes sociales.

Este ensayo nace de la necesidad de reflexionar la relación existente entre el amor como una estructura de pensamiento y praxis desde imaginarios que se expresan en mecanismos globalizados como la música y la fotografía, con el fin de analizar prácticas de amar que nos han sido enseñadas.

La estructura teórica y práctica que contiene este ensayo parte de la siguiente manera: en una primera parte me acercaré al concepto del amor, planteando algunas líneas reflexivas en las que, como seres sociales, nos educan y aprendemos a amar; como segundo elemento reflexivo iremos hacia la pregunta: ¿amar románticamente? El cuerpo como mediador del amor, seguido de las configuraciones del amor por medio de sus representaciones sociales en los espacios públicos; por último, la parte práctica en la que se contrastan algunos aspectos teóricos, a partir de las representaciones artísticas: la música y la 
televisión. Referente a este último punto, se tomarán en cuenta algunas canciones de "salsa" y telenovelas.

\section{Vivir felices para siempre en el país de las maravillas: la globalización como fábrica de "cuentos chinos" sobre amor romántico}

La Cenicienta, Blanca Nieves y los siete enanos, La Bella y la Bestia, entre otros muchos cuentos más, nos han acompañado como historias en las que se promueven y se proyectan dos únicas posibilidades para llegar a ser "felices para siempre": ser la princesa que será rescatada, o ser el príncipe azul que luchará por todo y llegará en corcel, lleno de valentía y holgura. Solamente imaginemos a esos dos personajes en cada uno de los momentos en los que hemos estado con parejas dentro de nuestras diversas relaciones. Tenían algo, sí, efectivamente, algo que nos hacía vibrar, sentir, pensar, proyectar una serie de características que no sabíamos de dónde venían ni por qué venían, pero eran nuestros "requisitos" infalibles para "ser felices". Fracaso rotundo cuando no llegaba a ser lo que pensábamos y, por lo tanto, el dolor y la desazón tiñeron el país de las maravillas.

Por esas experiencias no tan gratas - porque todas las personas las pasamos -, podría pensarse que han ido cambiándose las formas de relacionarse con nuestras parejas, y, por tanto, se han "bajado" los estándares con los que medimos y evaluamos las posibilidades. "No quiero una relación seria", suele ser alguna de las frases que dejamos salir o escuchar cuando empezamos a relacionarnos con una de esas personas que creemos potenciales parejas. Lo más interesante de esta dinámica podría ser aquella sensación que se está obteniendo tras ir un poco más allá de "no querer una relación seria" y adquirir un "compromiso" de mayor amplitud de lo que alguna vez fue considerado, y, por consiguiente, se "cerrarían espacios de consumo" de otras posibles experiencias excitantes y románticas.

Tal y como lo advierte Bauman (2015), la cultura de consumo, como la nuestra $-y$ agregaría la cultura globalizada- juega un papel fundamental dentro de las experiencias relacionadas con el amor, pues es una cultura que es "partidaria de los productos listos para uso inmediato, las soluciones rápidas, la satisfacción instantánea"; por consiguiente, son experiencias que se basan en una promulgación de resultados que no requieren esfuerzos prolongados, que poseen recetas infalibles, pero sobre todo, contra las posibilidades de riesgo a cualquier fracaso. En otras palabras, la promesa de que se "logrará la experiencia del amor", no es más que una forma de vender una mercancía, la cual, "seduce y atrae con su ostentación de esas características porque supone deseo sin espera, esfuerzo sin sudor y resultados sin esfuerzo" (p.22).

Por lo tanto, para Bauman (2015), llegar a enamorarse es una situación recurrente, o con demasiada facilidad. En efecto, estar enamorado, como lo dice Bauman (2015), es uno de los estados más comunes, y esto no sería de extrañar, ya que "podemos suponer (y con fundamento) que en nuestros tiempos crece rápidamente la cantidad de personas que tiende a calificar el amor a más de una de sus experiencias vitales, que no diría que el 
amor que experimenta en este momento es el último, y que prevé que aún la esperan varias experiencias más de la misma clase" (p.19). Asegurando lo anterior, este no debería ser asombroso, pues el contexto de la sociedad en la que nos encontramos ha ido influyendo hacia concepciones que son de mejor consumo, y esto se debe a que, no necesariamente, se han incrementado los niveles de exposición para alcanzar los estándares de exigencia que nuestras mentes necesitan, "sino que esos estándares son ahora más bajos: como consecuencia, el conjunto de experiencias definidas con el término 'amor' se ha ampliado enormemente" (p.19). Dicho esto, la concepción de lo que significa amor, va ligada a una situación de consumo: entre más relaciones se tenga, mayor el nivel de experiencia amorosa y, por tanto, se llega a creer que mayor capacidad amorosa se puede tener.

En tal contexto, dice Bauman (2015), el amor termina siendo una inversión, es decir, puede ser una experiencia en la que se podrían tener pérdidas y se podría despilfarrar toda la inversión hecha. Así lo plantean muchos expertos, según Bauman (2015), pues implica "dedicar tiempo, dinero, esfuerzos que hubiera podido destinar a otros propósitos, pero que no destinó esperando hacer lo correcto, y lo que usted perdió o eligió no disfrutar, se le devolverá en su momento, con ganancias" (p.29). Ahora bien, estas ganancias están, en mucho, ligadas a beneficios que generen satisfacción:

Si usted invierte en una relación, el provecho que espera de ella es en primer lugar seguridad, en sus diversos sentidos: la cercanía de una mano que ofrezca ayuda en el momento en que más la necesite, que ofrezca socorro en el dolor, compañía en la soledad, que ayude cuando hay problemas, que consuele en la derrota y aplauda en las victorias; y que también ofrezca una pronta gratificación. (p.30)

Sin duda alguna, el contexto actual de la globalización y la sociedad de consumo influyen en muchísimos de los elementos constituyentes de cultura, de las concepciones sobre las realidades sociales, tal y como lo he descrito en este apartado. Pero como se puede notar, el amor no es un proceso que sale de la nada, sino que se aprende. A continuación, se desarrollarán líneas de reflexión teóricas que se desprenden de una serie de autores y autoras que han trabajado la temática.

\section{Cuando los cuentos se vuelven nuestra realidad, ¿sueños, pesadillas y crisis existenciales? El amor como objeto de análisis}

1. "Érase una vez, en un pueblo muy lejano, un amor que fue aprendido". El amor como acción social: nos educan y aprendemos a amar

Uno de los deseos más buscados por parte de los seres humanos se refiere a poder amar a otra persona, y que esta nos corresponda. $\mathrm{Y}$ es que, en todos los momentos de nuestras vidas, así como algunas de las instituciones con las que tenemos nuestros primeros contactos conscientes, llámese la familia, grupos de pares (amigos o amigas), así como los medios de comunicación, nos hablan del amor. Incluso, no es un secreto 
que, desde la religión, el amor es uno de los ejes principales dentro del deber ser religioso, al menos desde lo católico.

De una $\mathrm{u}$ otra manera, todas estas formas nos han mostrado expresiones de lo que se cree es amor, o lo que quieren mostrarnos como tal. Sin embargo, el contexto y el tipo de sociedad son fundamentales en la transmisión del conocimiento de lo que es el amor, qué significa, cómo debería expresarse y con quién debería compartirse. Para Lagarde (2000), todas las formas en las que se ha transmitido el amor, socialmente hablando, han conformado una serie de creencias que están muy entrelazadas con mitos, y estos a su vez, son confundidos con fantasías, lejanas a lo que se podría encontrar en las realidades: “así, la primera y constante contradicción amorosa se establece entre la experiencia vivida y el mito" (p.9).

Los mitos y fantasías, como los menciona Lagarde, están contextualizados dentro de un contexto en el que nos dicen cómo ser y cómo vivir, calando significativamente dentro de nuestros imaginarios $\mathrm{y}$, por tanto, dentro de las relaciones sociales en la vida cotidiana. Se nos vende la idea de que amar es la mejor experiencia por vivir que podamos tener, pero dicha forma se encuentra de una manera estandarizada y basada en fantasías que nos transmiten y que todas las personas estamos sedientas de poder experimentar. Fromm (s.f.) indica que:

Todos están sedientos de amor, ven innumerables películas basadas en historias de amor felices y desgraciadas, escuchan centeneras de canciones triviales que hablan del amor, y, sin embargo, casi nadie piensa que hay algo que aprender acerca del amor. (p.3)

Por tanto, podemos notar que existen dos líneas dentro de la acción del amor: ser amados y amar. Para ambos casos, hay formas representativas que, desde los mitos y las fantasías, deben ser representadas socialmente. Es aquí donde tanto Fromm como Lagarde coinciden en que existen caminos que seguir, y estos están delimitados por procesos educativos socialmente construidos como mandatos inquebrantables y, por tanto, sea cual sea la relación, el amor siempre estará en juego, ya sea por medio de la representación del ser que busca ser amado, o de las personas que se desea amar. Lagarde (2000) explica que "En cada relación íntima, próxima, siempre está en juego el amor. En cada relación entre seres humanos se da una educación amorosa. Y cada relación personal es una relación pedagógica sobre amor" (p.13).

Por consiguiente, tener relaciones que constantemente nos enseñan sobre el amor, nos refleja que, según Lagarde (2000), estamos "en un aprendizaje continuo, en permanentes cursos intensivos sobre el amor. Nos educamos, nos re-educamos, nos educan. Y también nosotras educamos a otros y a otras" (p.13). En estas relaciones, en las que existe una forma dialéctica de construir el amor dentro de nuestros imaginarios, recaen todos aquellos mitos y fantasías del deber amar, es decir, aquellos deberes y prohibiciones. Según Lagarde (2000): "nos educamos y educamos en cuanto al sentido trascendente y filosófico del amor. En cuanto a los deberes del amor, en cuanto a las prohibiciones 
amorosas y en cuanto a lo que está permitido en el amor" (p.13).

El amor, al ser una experiencia aprendida, socialmente construida y en constante construcción, tal y como se ha mencionado anteriormente, genera uno de los dilemas subjetivos más complejos dentro de la vida amorosa de las personas: el conflicto entre el mito y la realidad. La persona, al estar en espera constante de algo que se le construyó durante los procesos de socialización y aprendizajes históricos, cultiva una mitología amorosa que es pieza fundamental dentro de nuestra concepción de mundo. Lagarde (2000) plantea que este conflicto es uno de los que golpea más fuertemente dentro de las personas, dentro de mi yo, pues esperar siempre esa forma mitológica en nuestras experiencias, genera dilemas sumamente graves que no sabemos cómo ressolver:

Todos los mitos aparecen como creencias, y con frecuencia no tenemos idea de cuál es la distancia entre el mito y la realidad posible. Y por eso, una fuente de continua frustración está en confundir lo que debe ser con lo que es. Otra fuente de frustración está en comparar a la persona amada con la persona amada en el mito. Y ahí nadie pasa la prueba. Otra fuente de frustración es aún más grave porque golpea autoestima: nosotras tampoco pasamos la prueba al compararnos con la amante que quisiéramos ser en nuestro mito. (p.68)

Sin duda alguna, todas las personas hemos pasado por la experiencia de pareja en la que nos sentimos sumamente felices, si y solamente si, se cumple con todas o la mayoría de las exigencias que han sido moldeadas dentro de nuestros imaginarios, es decir, nuestras fantasías o mitos. Parece que lo más complejo es aceptar que los mitos son solamente mitos, y que las fantasías, tal y como lo dice su nombre, serán siempre fantasías.

Este conflicto, que está basado en una relación de expectativa/realidad, no solamente es construido y aprendido, sino también generalizado en una sola forma de ser y de vivir. Entonces, nace la pregunta: ¿somos dignos de dar y recibir amor, ante el distanciamiento de las realidades con el mito/fantasía? Para Fromm (s.f.), tener mitos y fantasías "estandarizadas" relacionadas con el amor, se da a partir de lo que la sociedad contemporánea predica respecto a que todas las personas son iguales, es decir, todas las personas deben hacer las cosas igual, producir igual, ser iguales. La estandarización, por tanto, no solamente se da por cuestiones plenamente de producción, sino que también se da en las formas de ser, vivir y desear. No debe haber conflicto ni fricción, deben sentir convencimiento de que siguen sus propios deseos, y que estos deseos no son cuestionados, pues el amor dará el confort ante la angustia que pueden dar otras áreas de la vida cotidiana, como el trabajo, la rutina y el mercado, entre otros (p.9).

Ahora bien, una vez que hayamos entrado en esa fase de evaluación de la fantasía frente a la realidad, puede ser que entremos en otro proceso de aprendizaje del cómo amar $\mathrm{y}$, por tanto, esperamos que de nuevo surjan aquellos esquemas, pasos, 
modos, guías, entre otros, que nos den el marco por seguir para el "verdadero" o "correcto" ser que ama. Bauman (2003) explica que estamos en una sociedad en que se nos dice cómo actuar $\mathrm{y}$, con ello, validar nuestras posiciones sin tener que enfrentarnos con nosotros mismos, o con los "otros":

Los agradecidos destinatarios del consejo revisan las columnas sobre relaciones de los suplementos semanales o mensuales de los periódicos serios y menos serios buscando escuchar de las personas que saben lo que siempre han querido escuchar, ya que son demasiado tímidos o pudorosos como para decirlo por sí mismos; de ese modo se enteran de las idas y venidas de 'otros como ellos' y se consuelan como pueden con la idea.

Esta búsqueda constante que expone Bauman, validada por otras personas y expertos, es el reflejo de la necesidad constante de ser personas que deben mantener vivas las fantasías, por medio de confirmaciones de "otros" que en este momento son felices por recibir y dar amor. Este tipo de acciones deja de lado todas aquellas posibilidades que nos den la independencia necesaria para experimentar el amor de una manera muy propia y diferente, tomando en cuenta las historias de vida particulares, sin que se nos diga cómo y por qué. Este punto, sin duda, implica un apartado diferente a los planteados dentro de este escrito; sin embargo, es una línea para discutir en el futuro. Sin embargo, tal y como lo menciona Fromm (s.f.), el "fracaso" en el amor implica una lucha interna, aspecto con el que coincide Lagarde, que va más allá del fin del amar, sino más bien, en el hecho de para qué amar, y en esta línea, Fromm (s.f.) explica que el amar se relaciona con evitar estar en soledad y en la separatidad, el miedo a estos:

La necesidad más profunda del hombre es, entonces, la necesidad de superar su separatidad, de abandonar la prisión de su soledad. El fracaso absoluto en el logro de tal finalidad significa la locura, porque el pánico del aislamiento total sólo puede vencerse por medio de un retraimiento tan radical del mundo exterior que el sentimiento de separación se desvanece. (p.6)

\section{2. "Espejito, espejito, muéstrame ese cuerpecito". El amor entra por los ojos: amar románticamente por medio del cuerpo}

No es lo mismo amar desde un cuerpo de hombre que desde el cuerpo de la mujer. Y es que, como se mencionó en el apartado anterior, la vivencia de la vida amorosa de las personas está estrechamente relacionada con la experiencia de vida dada a partir de los aprendizajes y socializaciones del amor desde el ser hombre y ser mujer.

Bien lo plantea Fromm (s.f.), cuando toma como base la sociedad contemporánea a partir de la cultura, la cual tiene como rasgo característico el deseo de comprar. En efecto, según Fromm (s.f.), el hombre moderno posee su felicidad a partir de la "excitación de contemplar las vidrieras de los negocios, y en comprar todo lo que pueda, ya sea al contado o a plazos". La base de esto, indica el autor, es ser una persona 
"atractiva", sin importar si es ser hombre o mujer, ya que esto "significa habitualmente un buen conjunto de cualidades que son populares y por las cuales hay demanda en el mercado de la personalidad". Claro está, indica Fromm (s.f.), que el ser "atractiva" no basta con lo físico, sino también en poseer la capacidad de estar a la moda de la época y de serlo mentalmente (p.3).

Dicen que "el amor entra por los ojos", aquella frase popular que hemos llegado a utilizar para describir, en la explicación que Fromm nos dio sobre verse como una persona atractiva. Esto se encuentra estrechamente relacionado con las fantasías y mitos, que se desarrollaron en el apartado anterior, pues, ¿cómo presentarse como una persona atractiva si no es cumpliendo con las expectativas generadas por medio de las fantasías y los mitos?

Fromm (s.f) explica que esto es parte del concepto del amor romántico, el cual está muy relacionado con la sociedad occidental y, en especial, desde los Estados Unidos. Esto no es casual, pues este es uno de los países con mayores alcances en cine, industria musical y televisión, entre otros. Por lo cual, Fromm (s.f.) explica que estas fantasías y mitos construidos desde las industrias de la sociedad occidental permiten "consideraciones de índole convencional", y esto por supuesto, permea para que "la mayoría de la gente aspire a encontrar un "amor romántico", que le lleve "a tener una experiencia personal del amor que lleve luego al matrimonio" (p.3).

Amar es una mezcla indisoluble de las expectativas (mitos y fantasías) que se expresan por medio del cuerpo, que tiene que ser merecedor por medio del ser "atractivo". Pero, el cuerpo, al ser la parte más visible y tangente de los mitos y las fantasías, no es igualmente representado y construido por parte de los hombres ni de las mujeres. Para Lagarde (2000), el proceso de enamoramiento es una lucha de poder que margina a las mujeres de una posibilidad lejana más allá del ser adherida a los hombres. Esto, según la autora, implica que los hombres como seres amorosos, "han sido construidos de tal forma que para ellos el enamoramiento se acaba, pronto tiene fin”. Pero, ¿por qué la pasión se apaga en cuestión de tiempo? Lagarde (2000) explica que "en la mayor parte de los hombres el enamoramiento es una experiencia que se hace insostenible y el yo se cierra y todo termina". Por lo tanto, este es uno de los reflejos más importantes dentro de la configuración subjetiva del género (p.75).

Ahora bien, partiendo de que en el caso de los hombres se acaba el enamoramiento, para las mujeres sería el contraste marcado, es decir, estar siempre enamoradas. Esto implica que su yo, menciona Lagarde (2000), queda perdido ya que colocan a su pareja como el centro de su subjetividad $\mathrm{y}$, por lo tanto, el otro tiene la prioridad: "nuestro sentido de la vida queda ligado rotundamente al otro, haga lo que haga, nos ame o no nos ame, esté presente o se haya ido hace cuarenta años a comprar cigarros" (p.76).

Fromm (s.f.), en la misma línea de lo que plantea Lagarde, explica que el amar es una actividad que no es pasiva, al contrario, implica un "estar continuado" que puede describirse con un "carácter activo", 
el cual confirma que el amor "fundamentalmente es dar, no recibir" (p.11). Esta es una de las bases dentro de las concepciones del amor romántico, ya que no solamente es colocar a la otra persona como el centro de mi yo, sino que también es estar continuamente dando.

Pero, ¿qué es dar? Esta es la pregunta que Fromm (s.f.) plantea, misma que considero fundamental para comprender los ejes construidos socialmente, y que son pilares dentro de los mitos y fantasías que se nos construyen socialmente. En efecto, desde el punto de vista de lo que representa amar dentro del imaginario de todos y todas, implica no solamente la entrega y colocación del otro dentro de mi centro de subjetividad, y esto a su vez nos envuelve en una de las mayores ambigüedades. Según Fromm (s.f):

El malentendido más común consiste en suponer que dar significa 'renunciar' a algo, privarse de algo, sacrificarse. La persona cuyo carácter no se ha desarrollado más allá de la etapa correspondiente a la orientación receptiva, experimenta de esa manera el acto de dar. El carácter mercantil está dispuesto a dar, pero sólo a cambio de recibir. (p.11ss)

Por consiguiente, menciona Fromm (s.f.), amar no es solamente poseer como acción un sentido de sacrificio, en donde se debe dar, a tal punto que, a pesar de que esto puede ser doloroso, es una virtud por parte de la persona enamorada, pues acepta el sacrificio. Por lo tanto, "la norma de que es mejor dar que recibir significa que es mejor sufrir una privación que experimentar alegría" (p.12). Esta privación es una de las representaciones sociales más fuertes que posee el amor, pues va más allá del aceptarme como persona, sino que, además de aceptarme, debo aceptar a la otra persona aun antes que mi propio yo.

\section{3. "Adivina, adivinador(a), ¿a qué} lugar pertenezco yo?" Amor por medio de sus representaciones sociales en los espacios públicos/privados

El sacrificio, por lo tanto, no es solamente un acto de descolocación de mi propio yo, sino que es aquella forma de intentar poseer los merecimientos para amar. Prácticamente nos encontramos en un dilema en el que el amor nos hace pensar en si somos capaces de amar o de ser amados: cayendo en esa constante pregunta existencial de si seremos capaces de dar amor y cumpliremos con ser dignos de recibir amor. Y para ello, es necesario demostrar que somos capaces de aplicar esa práctica. Esto va muy relacionado con lo que se detalló en el apartado anterior, en donde para amar hay que mostrarse como una persona "atractiva", capaz de dar lo que la otra persona necesita y, por tanto, no solamente es capaz de amar, sino también de ser amado. Esta dinámica de exhibición de mitos y fantasías por medio del cuerpo, genera representaciones sociales que están muy íntimamente entrelazadas con los espacios, ya sean públicos o privados.

En efecto, para desarrollar este punto, es importante retomar lo planteado por Bourdieu (2000) y lo que explica Lagarde (2000), quienes diagraman una relación estrecha entre el amor, el cuerpo y los espacios sociales, en el entendido que, dentro de las dinámicas sociales cotidianas, 
hay una interacción constante por parte de estos tres componentes, que permiten construir un escenario de exhibición y acción. Bourdieu (2000), por ejemplo, plantea que las interacciones entre hombres y mujeres están enmarcadas dentro de las posibilidades de acción que se realizan dentro de lo público y lo privado. No se puede excluir que estas posibilidades están dentro de las relaciones de género, en las que Lagarde (2000) coincide, en el sentido de que la construcción social de las identidades de género delimita a los hombres y a las mujeres a mantener órdenes $\mathrm{y}$, por tanto, un sistema de oposiciones que coloca a las mujeres dentro del espacio privado y a los hombres dentro del espacio público. La dualidad no solamente queda delimitada en ello, sino que trasciende a lo simbólico, que también posee como eje central el cuerpo y, por tanto, el sistema de dualidades sería básico en la interacción de la pareja: público/privado, arriba/abajo, activo/pasivo (p.20).

Lo anterior nos hace comprender la explicación que plantea Fromm (s.f.) sobre cuáles deberían ser los caminos para poder alcanzar el "ser dignos de amor": en el caso de los hombres, tener éxito, ser poderoso y rico, tal y como el margen social de la propia posición económica lo permita. Mientras que, en el caso de las mujeres, ser atractivas por medio del cuido propio del cuerpo, de la ropa, es decir, ser bellas. Asimismo, dice Fromm (s.f.), "existen formas de hacerse atractivo, que utilizan tanto los hombres como las mujeres, tales como tener modales agradables y conversación interesante, ser útil, modesto, inofensivo" (p.3).
Ahora bien, en la práctica de la vida cotidiana, lo expresado anteriormente está muy ligado con las fantasías y los mitos que se construyen socialmente. No es lo mismo ser el hombre dentro de la relación, que ser la mujer. Y, según Lagarde (2000), el enamoramiento ha sido construido, social y culturalmente, para favorecer a los hombres, ya que estamos en una posición que nos hace ser protagonistas de nuestra propia vida y del mundo, es decir, tanto de la construcción y vivencia de mi yo - es colocado como el centro de mi yo - como desde la vivencia en los espacios públicos. Esto a su vez, según Lagarde (2000), termina favoreciendo a los hombres, pues somos quienes recibimos la dádiva de las mujeres, quienes colocan al otro en el medio de su yo, y que desde las funciones sociales de pasividad y de espacio privado, terminan "arreglando" o "mejorando" al hombre: "resuelven un conflicto que no habían resuelto, terminan un estudio que no habían terminado, emprenden un negocio nuevo, deciden emigrar realizando el sueño de irse a trabajar a otro país"; esto, por lo tanto, es una supremacía en el enamoramiento (p.76).

Por el contrario, las mujeres, bajo esa condición de "abajo", "pasivo" y de "privado" que detallaba Bourdieu, terminan colocándose en una condición de enamoramiento que se centra en el "dar, dar, dar". Lagarde (2000) explica que la mujer en esta condición de enamorada, busca solamente el beneficio y el mejoramiento del otro, pero que a cambio - como lo manifestaba Fromm - espera que el otro esté bien para que la ame. Así pues, "te doy para que me ames, y porque no tengo, y porque sólo necesito tenerte a ti" (p.76). 
No solamente basta con "dar, dar, dar", sino que, como indica Lagarde (2000), la relación termina siendo cada vez más compleja, ya que el dar y recibir plantea una seria cercanía o lejanía con respecto a los mitos y fantasías. Una de las complejidades más intensas dentro de las relaciones parte de la desigualdad en cuanto a dar y no recibir, esto principalmente en las mujeres, ya que, según Lagarde (2000):

Das y das y la otra persona más y más se retira. Y como esta reacción no la entendemos, nos produce choques constantes entre los anhelos de amor que tenemos, basados en los mitos, y en la realidad que vivimos. Muchas mujeres dicen: "no entiendo, cada vez le doy más y nada, ya no sé qué hacer, ya me hice la cirugía, ya aprendí a cocinar, ya no salgo de mi casa.” (p.77).

Por lo tanto, parece que una de las claves del amor y su construcción social permite creer que enamorarse exige sacrificios, y que esos sacrificios se basan en el autosacrificio.

\section{IV. ¡Se viene el "selfie" con banda sonora! Experimentos por medio de la escucha y la observación}

Como último punto por desarrollar, he decidido describir algunos de los elementos planteados dentro del escrito, para detallar aspectos básicos del amor y sus connotaciones, por medio de las representaciones artísticas latinoamericanas. Para ello, he seleccionado la música y la televisión, donde son las telenovelas y el género de la salsa los objetos de descripción. Sin profundizar mucho en los detalles, esta selección se dio por las razones desglosadas a continuación.

\section{Vivamos lo nuestro con muchos detalles: el ejemplo de la salsa como reproductora de mitos y fantasías} La música salsa, según Castro (2009), es un conjunto de ritmos y estilos musicales que poseen aportes de migrantes africanos, fusionados con lo nativo latinoamericano, lo español, moldeada, principalmente, con la combinación de músicos de Puerto Rico, Cuba y migrantes latinos en Nueva York. La salsa se convierte en abanderada latinoamericana, como forma de resistencia en Estados Unidos tras sufrir condiciones de hostigamiento y de constantes represiones económicas y político coloniales. Terminó siendo uno de los estilos musicales más reconocidos en el mundo y de mayor identificación latinoamericana.

La misma posición tiene Quintero (2002), quien sostiene que aparte de eso, desde Estados Unidos se había configurado por medio del cine "el ser latinoamericano" como exótico, tropical, exuberante, y que la salsa llegó a representar en parte la sonoridad latinoamericana (p.10). Ahora bien, Según Melo (2013), la música posee configuraciones culturales, las cuales - citando a Bourdieu - pasan a ser asumidas como naturales $\mathrm{y}$, por tanto, la música termina siendo una forma de comunicar significados que resultan ser socializadores, pues comparten marcos de referencia más o menos comunes que les suministran un conocimiento considerado cierto (p.686ss).

Una vez comprendida a grandes rasgos la relación de la música con los imaginarios 
sociales, se retomará el caso de las canciones que fueron seleccionadas para mostrar cómo se representa el tema del amor. Las canciones seleccionadas fueron: "Detalles" de Óscar de León (1991) y "Vivir lo nuestro" de La India junto con Marc
Anthony (1994). La primera fue seleccionada por ser uno de los "salseros" más reconocidos de Latinoamérica. En el caso de la segunda, alcanzó primeros lugares de los Billboard Top Latins Albums.

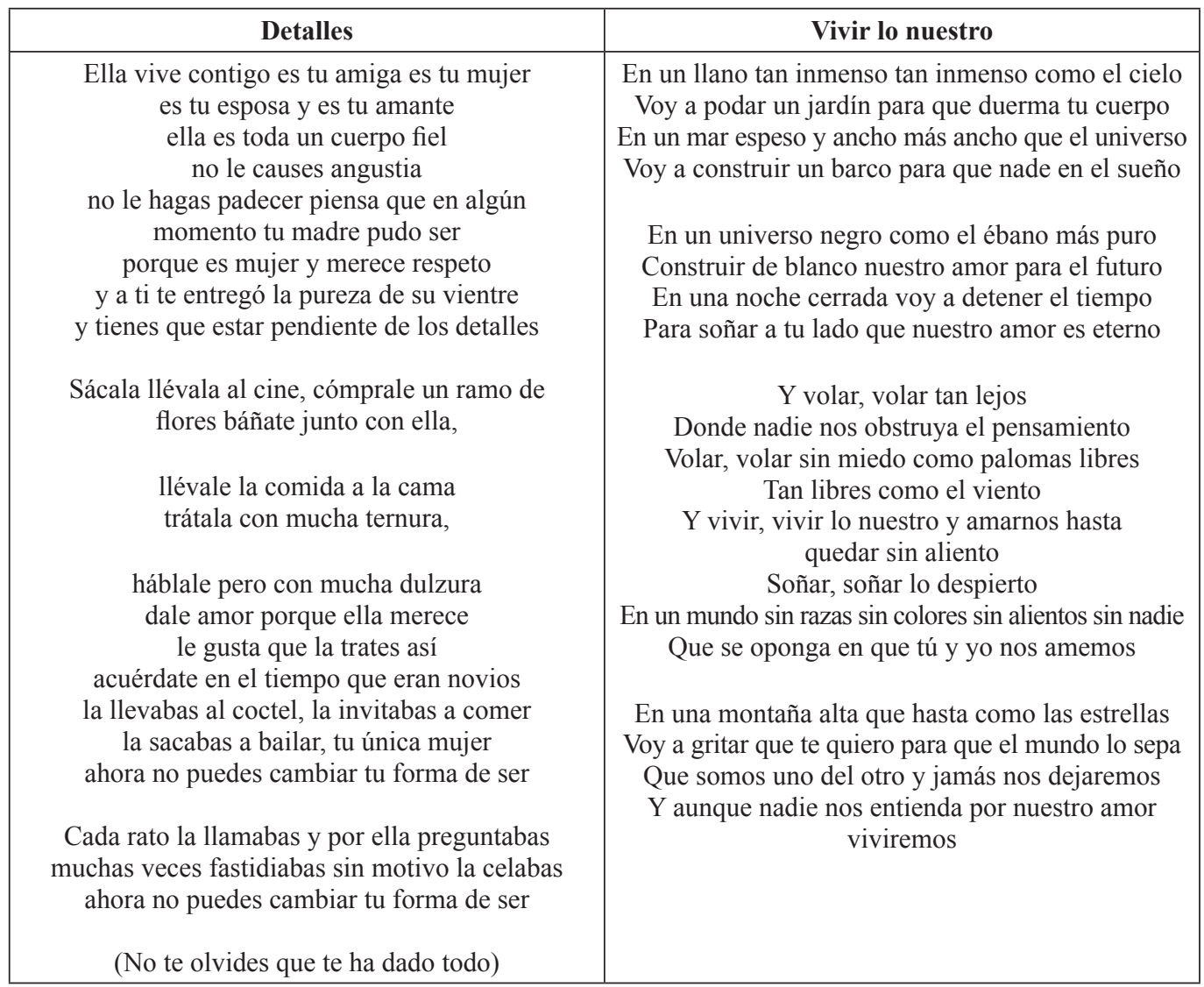

En el caso de la canción "Detalles", se puede mostrar cómo la letra describe:

- El hombre en el proceso de conquista se muestra como aquella persona "atractiva", ser una persona activa dentro del margen de la sociedad contemporánea. Asimismo, el hombre ha dejado de estar "enamorado", y pareciera que fue un hombre que tuvo un plazo muy activo y que ejecutaba detalles que correspondían a "dar".

- La mujer se muestra como aquella que está en constante estado de "enamoramiento", es decir, estar enamorada. Ella no ha dejado de "dar, dar, dar", lo ha dado todo, el cuerpo, la dulzura, su vientre. 
- Hay una evidente relación entre el mito/fantasía con respecto a las realidades. Y es que el tema de fondo en la canción muestra que existe una relación actual que está más apegada a la realidad que al mito o la fantasía. Esa lista de "detalles" que debe realizarse, es el reflejo pleno de lo que es la fantasía, de ese constante ser enamorado, de sacrificio, de entrega y de permanente ser "atractivo".

Para la segunda canción, "Vivir lo nuestro", las siguientes son algunas líneas de discusión:

- La canción presenta dos partes; es la primera una concepción de cómo hay contrastes de lo que significa la libertad, los colores, los sueños, pero que esto sirve como ambiente de entrega por parte de ambos.

- Muestra a una pareja que se dedica a "dar, dar, dar", en donde no hay nada "ni razas, ni colores", que permite la entrega total y que la forma de vivir el amor es por medio de entregarse al "otro", dejar centralizada a la otra persona dentro de mi yo, y aunque nadie entienda la relación, no habrá ningún problema, pues esto implica vivir el amor tal y como se construye desde la fantasía o el mito, entremezclado con el eterno estado de enamoramiento.

\section{Mitos y fantasías en sesión fotográfica: el retrato de amores por medio de cuerpos perfectamente consumistas}

Tal y como lo indican De Miguel y Ponce (1994), la fotografía es una de las herramientas de análisis social con alcances interesantes en las ciencias sociales. En efecto, si se parte del concepto y características de la fotografía, estos se pueden considerar como "actos sociales", ya que permiten "congelar un instante o momento decisivo, que permite ser visto, revisto, interpretado" (p.84). Según los autores, la fotografía ha cumplido con un papel fundamental en las diversas sociedades y culturas dentro de la historia. Para evidenciar lo anterior, De Miguel y Ponce (1994) mencionan ejemplos del papel de la fotografía en actos como los ritos de paso, tales como bautizos, bodas, graduaciones, cumpleaños y viajes, entre otros. Asimismo, otro ejemplo interesante dentro del papel de los actos sociales, refiere al primer día de escuela, o bien, se fotografiaba a los muertos, acto que según los autores ya no se realiza (p.84).

En otras palabras, la fotografía es una herramienta social que permite reflejar momentos específicos sociales, en donde se capturan - por medio de momentos, ritos, y otros papeles sociales - las situaciones de comunidades, familias y personas, entre otras. Así pues, como lo detallan De Miguel y Ponce (1994), "la fotografía contribuye a la construcción de la realidad social. Cada vez es más importante la imagen en las ideas que se tienen de la sociedad, de los roles sociales, de las normas sociales" (p.86).

Por tanto, la fotografía no es solamente una herramienta que permite la construcción de las realidades sociales, sino también una herramienta metodológica de importancia para los estudios sociales. Así pues, como lo indican De Miguel y 
Ponce (1994): "la fotografía puede ser utilizada para explicar visualmente los males sociales, los problemas de la sociedad. Permite describir comunidades, familias e incluso provocar la acción social" (p.86).

Mi idea central con la fotografía es poder visualizar, en lo concreto de las realidades, cómo el cuerpo representa las formas de lo que ha sido forjado en abstracto con los mitos y fantasías. Y es que, ¿cómo sabemos cuándo una pareja de personas posee una relación amorosa? Y esta pregunta es básicamente la que un amigo me consultó cuando le comenté sobre mi idea de desarrollar este escrito. Él me pidió que le explicara cómo yo podía representar a una pareja enamorada sin tener que pedirles que posaran para mi propia cámara. Y pensé, ¿para qué pedir que posen para mí cuando tenemos las redes sociales y una gran cantidad de personas que están colocando fotografías en compañía de su pareja, con largas descripciones y "emoticones" que reflejan un estado de enamoramiento activo?

Justamente parto de ese argumento para delimitar y justificar mi búsqueda de evidencias corporales. Para el análisis corporal, tomé en consideración los siguientes criterios para las fotografías: a. que fueran expuestas en alguna de las redes sociales: Instagram o Facebook; y, b. que fueran públicas, es decir, que cualquier persona que fuera contacto de estas personas pudiera tener acceso a ellas, en el entendido de que al colocarlas o "subirlas" en dichas redes, las hace de "dominio público" ${ }^{1 "}$.

Asimismo, tras una serie de conversaciones con personas con conocimientos en fotografía, así como las lecturas referenciadas anteriormente, se consideraron los siguientes criterios de análisis para las fotografías: a. Posición corporal en pareja: miradas entre sí y hacia la cámara; b. Posición corporal de manera individual (hombres y mujeres); c. Sitio y situación en la fotografía; y, por último: d. ¿Qué mitos y fantasías se logran interpretar? Otro de los elementos por considerar será que las fotografías fueron acomodadas bajo un orden específico que los mitos y las fantasías nos arrojan, es decir, la etapa de enamoramiento, como lo desarrollé teóricamente, posee una evolución que va desde el ser una persona apta, hasta llegar al matrimonio. Es justamente lo que se pretende con la secuencia fotográfica.

1 Reconozco que este punto es bastante complejo y posee una serie de posiciones diversas y debatibles. Sin embargo, parte de este ejercicio de reflexión se basa en retomar puntos de la vida cotidiana que han sido naturalizados, a tal grado, que no se cuestionan y simplemente se dan por sentados. Una persona puede subir cualquier fotografía a las redes sociales, y esta será, sin duda alguna, expuesta de tal forma, que sirva para validar la relación o la situación con los denominados "likes". Insisto, no es parte de este ensayo desarrollar este debate; sin embargo, a futuro se podría considerar como uno de los elementos para argumentar con diversos autores y autoras. 
Secuencia 1. Iniciando el camino (Fotografía 1 y 2)
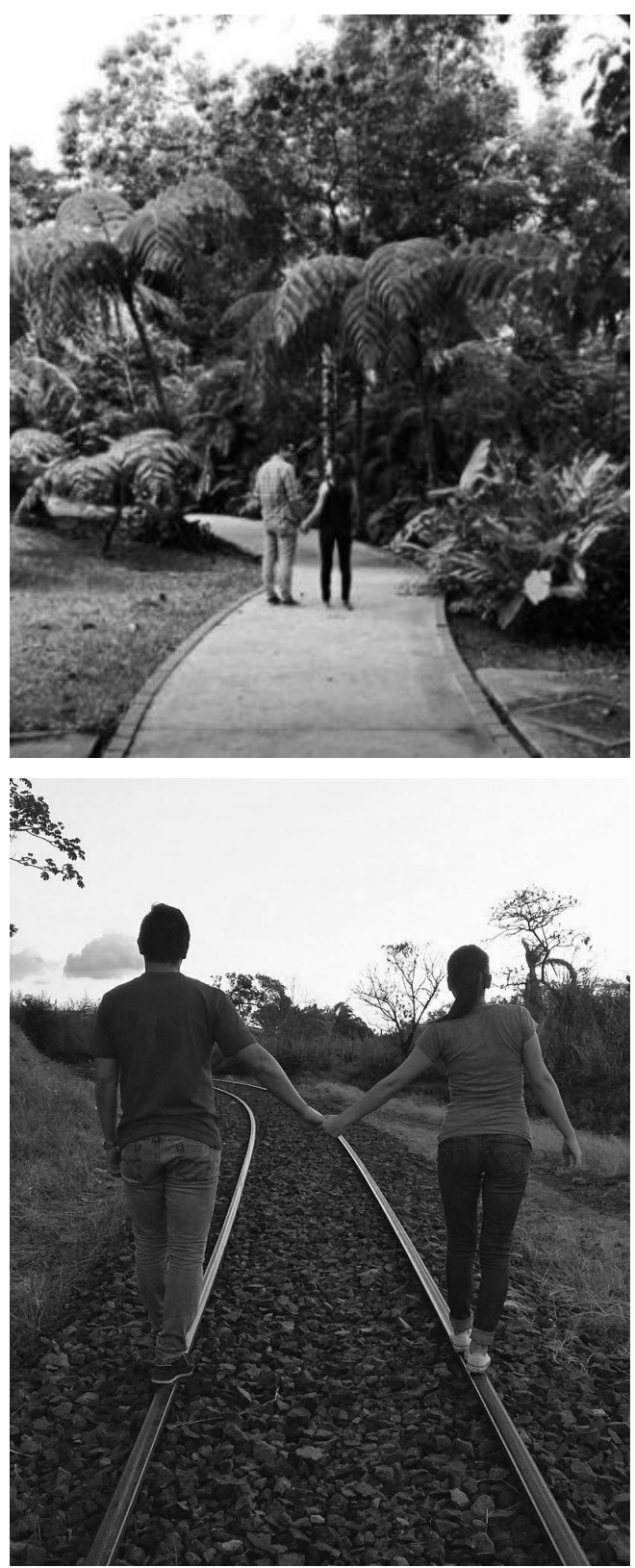

2 Fotografías aportadas y autorizadas por Ximena Madrigal Salazar, dueña de ambas.
Considerando los criterios de análisis, en la secuencia 1 , se desprende que:

\section{a. Posición corporal en pareja: miradas entre sí y hacia la cámara}

Es sumamente llamativo lo que esta pareja (es la misma en ambas) muestra en las fotografías. Sin duda alguna, la posición corporal refleja un deseo de mantenerse en un cambio, que está guiado y delimitado hacia un rumbo. En ambos casos, el horizonte está visualizado como el camino por seguir, y otro aspecto corporal que hace entender que son pareja, es que se encuentran tomados de la mano. No solamente esto es reflejo de que como pareja siempre deben estar unidos, sino que la unidad es la razón para mantenerse dentro del camino, ya sea este un camino dificultoso como el de la línea del tren con piedras, o uno llano como el de cemento.

Dentro de la secuencia 1, la primera fotografía muestra que son una pareja que se mira y se compenetra, como aquellas parejas que conocen que son "el uno para el otro", mientras que en la segunda fotografía, no hay necesidad de mirarse; tomarse de las manos es suficiente indicador de poder mantenerse unidos dentro de la línea.

\section{b. Posición corporal de manera indivi- dual (hombres y mujeres)}

Llama la atención cómo la pareja está ubicada en la misma posición, es decir, no varían su ubicación. El hombre se encuentra en la izquierda, mientras la mujer en la derecha. La estatura es uno de los elementos más naturalizados dentro de las parejas, y que el hombre sea de una estatura mayor 
a la de la mujer representa uno de los mitos más fuertes dentro de los imaginarios del amor. A pesar de esas características, se mantiene una cierta distancia entre uno y otro; pareciera que, dentro de la dinámica de lo romántico, la pareja da a entender que cada uno tiene una posición muy clara dentro de la relación, y esta se mantiene dentro de un camino que seguir.

\section{c. Sitio y situación en la fotografía}

La situación es muy clara: el camino por seguir es en pareja. No importan las dificultades, ni la forma del camino, este es "el camino". No hay situación especial en cuanto a evento propiamente dicho, pero sí la hay en lo simbólico de forjamiento de un presente que está encaminado a ser compañía uno de la otra y, por supuesto, esto se ve representado por la toma de la mano entre ambos.

\section{d. Mitos y fantasías desde la fotografía}

La necesidad de sujeción de la otra persona es un imperativo dentro de las dinámicas de las parejas. Existe un imaginario de un camino que seguir, que deben mantener, sin importar el sitio, ni el momento del día. Este es "el camino" con "la persona".
Secuencia 2: la aventura en compañía (Fotografías 3 y 4$)^{3}$
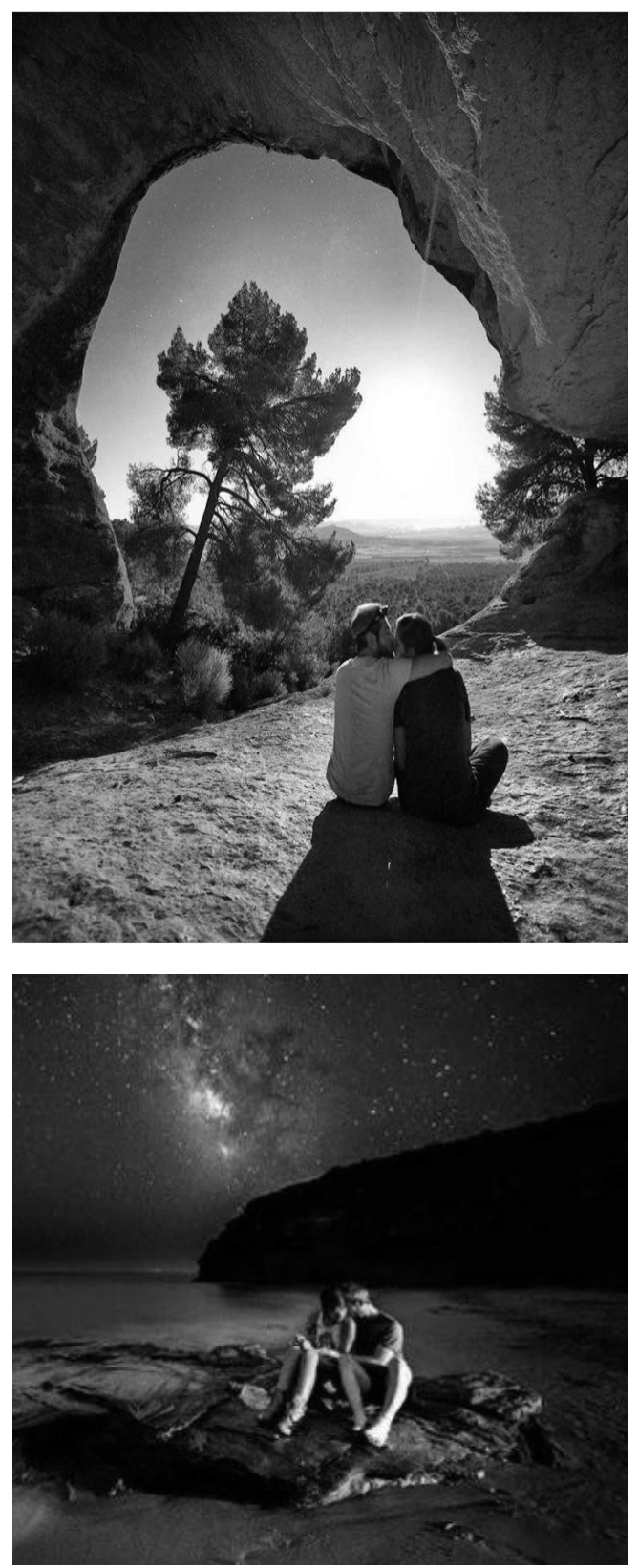

3 Fotografías aportadas y autorizadas por Andrea Mora Zamora, dueña de ambas. 
Considerando los criterios de análisis, en la secuencia 2, se desprende que:

\section{a. Posición corporal en pareja: miradas entre sí y hacia la cámara}

La etapa siguiente representada por esta pareja muestra una situación un poco distinta a la primera secuencia, es decir, en la primera encontramos un camino por seguir, el cual implica una posición específica dentro de la relación y en un camino en común. En esta secuencia, podemos observar que no existe un camino específico, pero la selección del lugar y la ubicación corporal de la pareja trascienden en intenciones de aventura por parte de la primera. En efecto, como pareja, se muestran sentados dentro de un suelo que es totalmente irregular, pero que la irregularidad se compensa con la cercanía de la pareja. La mirada, en ambos casos, se centraliza en la pareja, en donde la sujeción del hombre hacia la mujer es sumamente clara.

La primera secuencia mostraba cuerpos de pie, que reflejaban una posición distinta a esta secuencia, que muestra una forma muy relajada de estar con "el otro". Esto lo confirma la no visualización hacia la cámara, pues la posición corporal es provocada (o al revés), por una necesidad de concentrarse en la otra persona $\mathrm{y}$ que esto genere una posición rotunda de focalización $\mathrm{y}$ centralización de mi yo frente al otro.

\section{b. Posición corporal de manera indivi- dual (hombres y mujeres)}

La primera secuencia queda lejana de la segunda secuencia en este aspecto. Efectivamente, la posición de la mujer refleja una cierta comodidad, una sensación de confort por estar "protegida" por el hombre, quien toma una posición activa de protección y de acción, vistas por medio de sus brazos. Podría lanzarse la idea de que, en el caso de lo exótico y la aventura, hay una cierta necesidad de tomar roles reflejados por el cuerpo. Por último, al igual que en la primera secuencia, en esta la mujer y el hombre tienen una posición dentro de la fotografía, aspecto que puede ser visto como coincidencia, pero desde lo simbólico, pareciese que esto representa una posibilidad de visualizar que cada uno posee un rol y que se mantiene.

\section{c. Sitio y situación en la fotografía}

Ninguna de las fotografías aquí presentes va a superar el nivel de belleza escénica y, por tanto, de representación simbólica de lo que está viviendo como tal esta pareja. Desde los mitos y fantasías que se han trabajado en este ensayo, esta relación muestra que hay que movilizarse de manera exótica en pareja, para generar sensaciones que mantengan un estatus de relación que va más allá de las formas tradicionales de relacionarse.

\section{d. Mitos y fantasías desde la fotografía}

El ser una persona adecuada para la aventura en pareja se aúna a la necesidad de ser reproductoras de roles corporales que se centran en el ser protegida y en el proteger. Asimismo, debo confesar que este tipo de fotografías muestra un estilo de vida que no es alcanzable para la mayoría de las parejas, a no ser que se tengan ciertas condiciones económicas y de capital cultural. 
Secuencia 3: el amor con tintes de mercado (Fotografías 5 y 6$)^{4}$
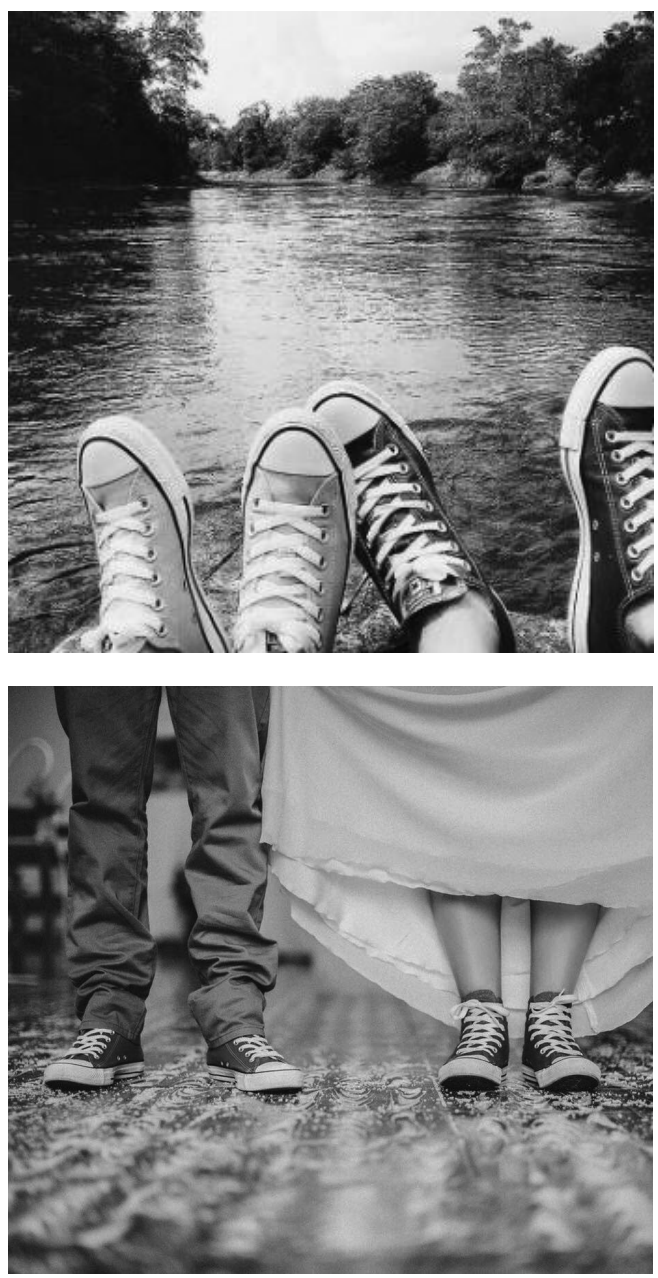

4 Fotografía 5 (izquierda) aportada y autorizada por Ximena Madrigal Salazar, dueña de esta.

Fotografía 6 aportada y autorizada por Allan Núñez Rosales, dueño de esta.
Considerando los criterios de análisis, en la secuencia 3, se desprende que:

\section{a. Posición corporal en pareja: miradas entre sí y hacia la cámara}

En esta secuencia, existe la particularidad de que se centra en una parte específica del cuerpo, eso sí, en pareja. Los pies son los que permiten una gran cantidad de dinámicas en pareja y que han sido retomadas por medio de estas fotografías. Lo llamativo de esta imagen refiere al estilo único con el que ambas personas utilizan el mismo tipo de zapatos, a pesar de que no son las mismas personas. El lugar donde se encuentran las dos parejas difiere por ser espacio abierto y espacio cerrado, pero no en la representación simbólica de que se encuentran juntos, con los mismos estilos de zapatos, listos para salir hacia la dirección del camino que en uno está de frente a la cámara, y en el otro, está detrás de la cámara, pero que en esencia está de frente a las dos parejas.

\section{b. Posición corporal de manera indivi- dual (hombres y mujeres)}

La posición de los pies, en el caso de los hombres, es levemente diferente a la posición de las mujeres. Se ha construido la idea de que las mujeres no pueden optar por posiciones en donde exista una apertura de sus piernas, mientras que esta no es una restricción por parte de los hombres. Esto ocurre en ambas parejas, pues se puede notar cómo la apertura de los hombres es mayor que en las mujeres. Por último, el color de las tenis en la primera fotografía, es claramente demarcado para el hombre y para la mujer. Lo llamativo en 
la segunda fotografía es el uso del mismo color, como aquel consenso en el que se pueden elegir rupturas pequeñas dentro de los rituales significativos en el amor, como lo es el matrimonio. Asimismo, pesar de mantener el color blanco en la novia, el novio utiliza un color distinto al negro que el novio debe utilizar.

\section{c. Sitio y situación en la fotografía}

Las situaciones varían; sin embargo, me parece que las formas de relacionarse con la otra persona es lo que marca la situación. Similar a la primera secuencia, la primera fotografía es más un reflejo de un camino que seguir, con las mismas condiciones (tenis), situación que es idéntica a la segunda, en donde el camino ya es prácticamente "seguro", pero con las mismas condiciones (tenis).

\section{d. Mitos y fantasías desde la fotografía}

Pareciera que el mito más llamativo en esta secuencia refiere a que hay igualdad de condiciones en ambas personas y en ambas parejas, por utilizar la misma marca de zapatos tenis.

\section{Secuencia 4: El príncipe azul logra la con- quista de la doncella (Fotografía 7 y 8$)^{5}$}
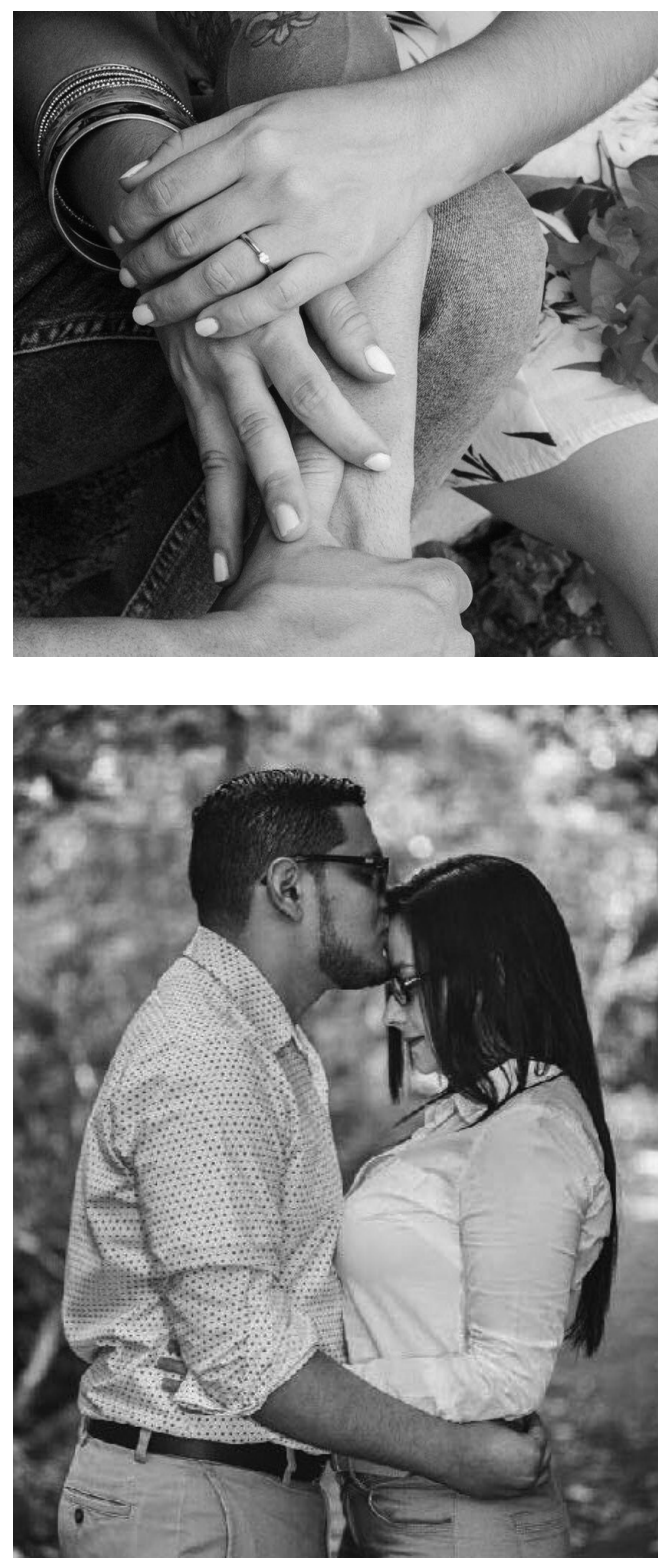

5 Fotografía 7 (izquierda) aportada y autorizada por Douglas Molina, dueño de esta.

Fotografía 8 aportada y autorizada por Stephanie Araya Jiménez, dueña de esta. 
Considerando los criterios de análisis, en la secuencia 4, se desprende que:

\section{a. Posición corporal en pareja: miradas entre sí y hacia la cámara}

El compromiso es una de las situaciones más esperadas dentro de las fantasías y los mitos del amor y el enamoramiento. La entrega del anillo, la sesión fotográfica, la búsqueda de cómo interpretar el amor que se siente por la otra persona, es lo que busqué ejemplificar con esta secuencia. En efecto, la cercanía de las parejas es notable, es decir, el compromiso da la posibilidad de que las personas que lo componen hayan "ganado el derecho" de poder ser más cercanas y poseerles sutilmente. Esto es lo que se ve reflejado dentro de la posición corporal de la pareja. $\mathrm{Si}$ bien es cierto, en la secuencia 2 notamos posiciones corporales muy cercanas, el escenario sí es totalmente diferente a la otra en mención, pues lo exótico y la aventura misma del enamoramiento parecen ser ya superados por una estabilidad y seguridad total en esta secuencia. En la fotografía uno, por ejemplo, la posición de los brazos y las manos entrelazados, mostrando una forma de sujeción de los brazos de la mujer sobre los del hombre, que están prácticamente pasivos, pero fuertes, cumpliendo ese rol de dar, mientras que el de la mujer, el de recibir. Otro elemento interesante es la vestimenta e indumentaria del hombre, quien posee una ropa "normal" del ser hombre, mostrando parte de su corporalidad masculina que se establece como fuerte, por medio del tatuaje y el "jeans". Mientras que la mujer utiliza un vestido, que está acompañado de accesorios en su brazo que son reconocidos como femeninos, y que son acompañados por la suavidad de las flores.

Lo interesante en esta secuencia refiere a la posición de la pareja frente a la cámara, en la que, por primera vez, las parejas muestran un cierto tipo de tranquilidad, donde buscan más ser el centro de atención, diferencia sustancial a la que se observó dentro de las dos primeras secuencias, donde abrían la escena al contexto del camino y la aventura exótica. En este caso, la posición corporal de pareja es una posición que centraliza la fotografía en la unión de los cuerpos, y en la tranquilidad que esta unión da hacia la pareja.

\section{b. Posición corporal de manera indivi- dual (hombres y mujeres)}

En el caso de los dos hombres, podemos observarles desde una posición tradicional de "ser hombres", es decir, la necesidad de observarles como la persona que corporalmente protege y que es capaz o merecedor del amor que va a recibir. En el caso de la primera fotografía, se puede notar cómo se centra en que su capacidad de ser hombre recibe y protege corporalmente a la mujer. Esto sucede de manera muy simbólica por dos puntos en referencia: el primero es el anillo, en donde la única persona que lo posee es el cuerpo de la mujer, lo cual quiere decir que se "encierran" uno dentro del otro, cumpliendo claramente el mito o fantasía de que se está en camino a estar "felices para siempre", gracias al acto bondadoso del "príncipe azul" que conquistó a la "doncella".

En el caso de la segunda fotografía, es algo similar. Si observamos la vestimenta 
de manera individual, se pretendió inicialmente poder mostrarse como equivalentes, y a su vez, listos para poder asumir con igualdad el camino del compromiso. Por otra parte, la posición activa de conquista por parte del hombre, quien envuelve por medio de un beso en la frente a la mujer, que espera pasiva y con sentimiento ese beso del "príncipe".

\section{c. Sitio y situación en la fotografía}

La situación misma que se analizó en los dos puntos, la retomo acá: el compromiso. Es aquella situación que no expone otra cosa que el ritual de lo que en apariencia significa "entregarse uno a la otra", en donde no se expone otra cosa más que la pareja en dicha unión.

\section{d. Mitos y fantasías desde la fotografía}

Claramente se pueden encontrar muchos de los mitos consolidados en esta secuencia. Trataré de retomar algunos de estos: el primero, considero que es el de la necesidad de comprometerse con la otra persona, y esto significa ubicar a la otra persona en el centro y dejar mi yo como secundario. Esto se puede observar en la ubicación corporal de ambas parejas. El segundo, pienso que se ubica en la necesidad de representarse como personas iguales y entrelazadas por medio del cuerpo, y otros elementos simbólicos, como lo es el anillo, para poder acompañarse hacia el camino que referiría a la última parte de los mitos y fantasías: "vivir felices para siempre".

\section{Secuencia 5: ...Y vivieron felices para siempre (Fotografía 9 y 10)}
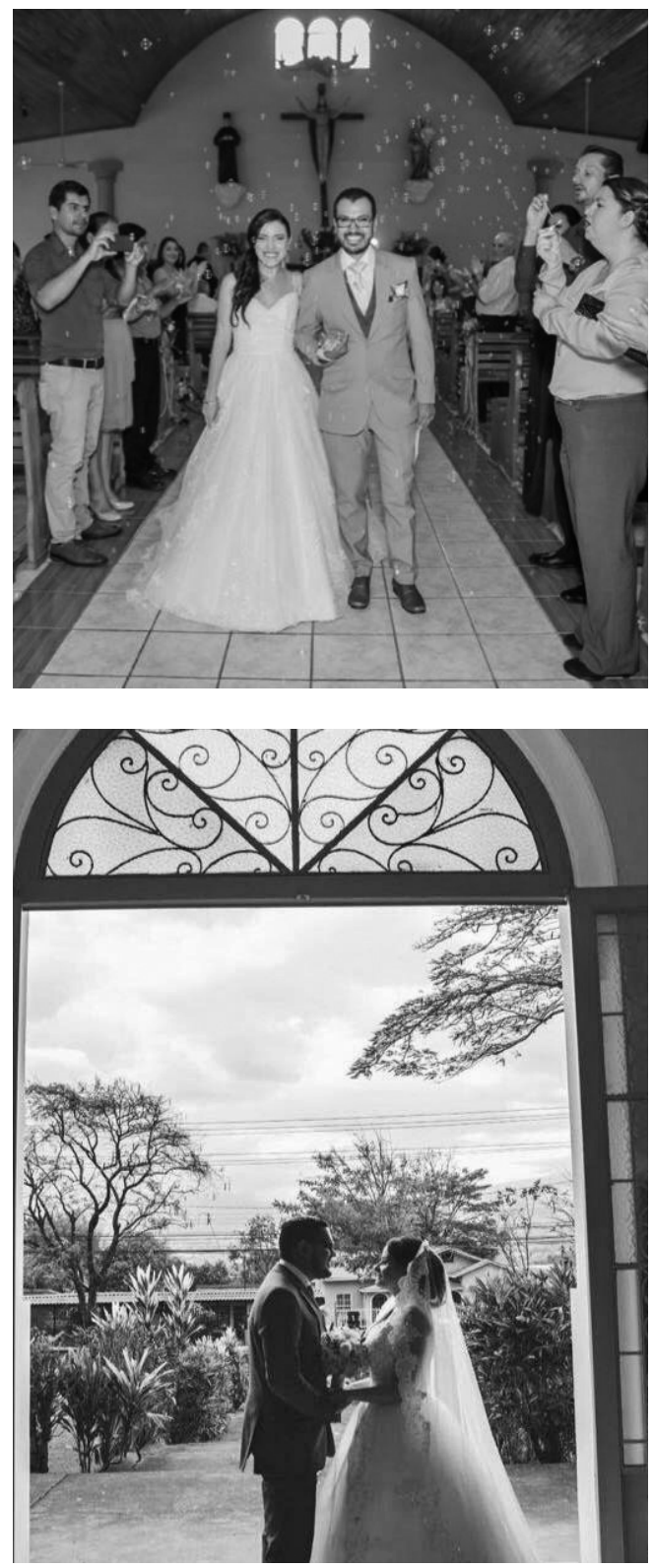

6 Fotografía 9 (izquierda) aportada y autorizada por Stephanie Araya Jiménez, dueña de esta.

Fotografía 10 aportada y autorizada por María Vanessa Conejo Chaves, dueña de esta. 
Considerando los criterios de análisis en la secuencia 5, se desprende que:

\section{a. Posición corporal en pareja: miradas entre sí y hacia la cámara}

La pareja ha cumplido con todas las "etapas" necesarias para culminar con el ritual del "inicio" del matrimonio. Aquel mito y fantasía necesarios de poder cumplir como pareja que ubica la unificación ya consolidada y pública con el compromiso, no solamente personal, sino institucional, legal y, sobre todo, espiritual. La posición corporal de las parejas, en ambas fotografías, refleja la ubicación centralizada de las parejas que han asumido dicho evento, y significa o implica muchísima seguridad frente a la persona. Y esto se nota en la mirada profunda que intenta reflejarse en la primera fotografía, mientras que, en la segunda, la pareja no se mira, pero miran profunda y felizmente a la cámara. No se puede omitir la forma de entrelazarse, es decir, las manos juegan un papel fundamental dentro del ritual, y la sujeción de estas implican una capacidad de aferrarse mutuamente, para llegar a cumplir con el camino de "vivir felices para siempre".

\section{b. Posición corporal de manera indivi- dual (hombres y mujeres)}

Sin duda alguna, hay una reproducción clara de aquellos rituales que los mitos y las fantasías establecen prácticamente como obligatorios. El primero, en el caso de las mujeres, vestirse de blanco, que implica una proyección de pureza en que la mujer "debe estar". Mientras, el hombre, representa una "elegancia", muy similar a aquellas situaciones en las que los príncipes rescatan a las doncellas. Esta es una clara situación, donde el mercado y la globalización enmarcan el "deber ser" dentro del ritual, pues las formas y los tipos de vestimenta que utilizan, tanto el hombre como la mujer, no son de costos menores. Implican una "inversión" que sea "acorde con la situación”, y que al ser en una única ocasión en la vida de la pareja, es justificación que no debe ser cuestionada.

\section{c. Sitio y situación en la fotografía}

Esta es una de las situaciones más tradicionales que se pueden captar por medio de la fotografía. Tal y como lo describí dentro de las funciones de la fotografía, consisten en captar momentos y rituales importantes socialmente. Y sin duda, esta secuencia muestra cómo se cumple. A parte de esto, otro aspecto fundamental es el sitio donde se encuentran, ya que en ambas fotografías se logra evidenciar que se están dentro de una iglesia, representando aquella sujeción espiritual que las parejas "deben” cumplir.

\section{d. Mitos y fantasías desde la fotografía}

Por último, queda claro que la secuencia final representa aquella vía única e ineludible de alcanzar la plenitud, pues para ser felices para siempre, hay que pasar por los actos protocolarios, sociales, institucionales y espirituales, entre otros.

\section{Conclusiones}

El tema del amor y el enamoramiento es uno de los más complejos y apasionantes que he logrado trabajar. Es tan interesante, que cerrar la discusión con estas páginas sería demasiado atrevido, al contrario, 
ha salido una gran cantidad de elementos analíticos que podría concluir por medio de las siguientes líneas de reflexión:

- Amar es una acción social, histórica y aprendida. Estamos en un constante proceso de aprendizaje y, además, enseñamos a las demás personas a amar.

- Amar tiene una influencia importante de la sociedad contemporánea, la cual enmarca las fantasías y los mitos que se pueden construir desde la música y la fotografía

- La misma sociedad contemporánea exige que debemos ser cuerpos que se exhiben, para mostrar que somos las personas adecuadas y cumplidoras de las fantasías y los mitos. Para ello debemos consumir y moldear nuestros cuerpos con vestimentas acordes a la aventura que culminaría en el ser felices para siempre.

- $\quad$ El mercado es uno de los precursores del amor y del enamoramiento. No es solamente consumir como pareja, sino que el mantener el enamoramiento y la aventura del amor tiene un costo material.

- El género es un eje realmente importante dentro de los procesos de aprendizaje y vivencia del amor, ya que no es lo mismo el proceso de aprendizaje y vivencia del enamoramiento por parte de los hombres que de las mujeres.

- En el caso de las mujeres, el sacrificio, "dar, dar, dar", es la base del enamoramiento, un estado constante, y que implica ubicar al otro dentro del centro del yo.

- En el caso de los hombres, se trata de recibir y mejorar cualquier ámbito de sí, guiado por su pareja, además de mantener su yo como centro de todo y de tener un proceso de enamoramiento delimitado.

- El espacio público y el privado se vuelven importantes dentro de la exhibición y de la reproducción de los mitos y fantasías.

- La música y la fotografía son reproductoras de las fantasías/mitos, los cuales ejemplifican todos los conceptos que se han analizado.

- No hay una única forma de vivenciar el amor; sin embargo, debemos acercarnos a comprender cómo nos llegaron los mitos y fantasías, para poder romper con ciertas estructuras, que nos hacen ser como somos dentro de la vivencia del amor y el enamoramiento.

Hay que mencionar que, como ejercicio, las fotografías presentan una serie de elementos sumamente interesantes a nivel de análisis de las rupturas en cuanto a las fantasías y los mitos, y se resignifican a partir de las experiencias propias dentro de los procesos de construcción de la historia de la pareja. Ejemplo de ello, son las tenis dentro de la fotografía $X$, en la cual el formalismo del matrimonio, se hace único y particular como pareja a partir del uso de las tenis y no de los zapatos, además de los colores y los significados representativos dentro de la fotografía. 


\section{Bibliografía}

Bauman, Z. (2015). Amor líquido. México: Fondo de Cultura Económica.

Bourdieu, P. (2000). La dominación masculina. Barcelona: Editorial Anagrama.

Castro, C. (2009). La salsa: una propuesta de sus heterogéneos orígenes culturales y una dilucidación de sus perspectivas musicales. Revista La Retreta, año II, No. 1, enero-febrero 2009. Recuperado el 20 de junio de 2017 de: http://www.laretreta. net/0201/salsa.pdf

Fromm, E. (s.f.). El arte de amar. Recuperado el 20 de junio de 2017 de: https://www.angelred.com/biblioteca/erich-fromm-el-arte-de-amar.pdf

García Canclini, Néstor (1995). Consumidores y ciudadanos. Conflictos multiculturales en la globalización. México: Grijalbo. Recuperado el 20 de junio de 2016 de: https://antroporecursos.files.wordpress.com/2009/03/ garcia-canclini- n-1995- consumidores-y- ciudadanos.pdf

Lagarde, M. (2000). Claves feministas para la negociación del amor. $M e$ moria de Puntos de Encuentro. Managua, Nicaragua. Recuperado el 20 de junio de 2017 de: http://www.caladona.org/grups/uploads/2013/04/ claves-feministaspara-el-poderio-yautonomia_mlagarde.pdf

De Miguel, J. y Ponce, O. (1994). Para una sociología de la fotografía. Revista Española de Investigaciones Sociológicas - REIS, N84, pp. 83-124. Consultada el 10 de enero de 2017 desde http://reis.cis.es/REIS/PDF/ REIS_084_08.pdf
Melo, L. (2013). La música y los músicos como objeto sociológico. Denken Pensée Thought Mysl..., Criterios, $\mathrm{n}^{\circ} 40$, febrero 2013. Recuperado el 01 de agosto de 2017 de: http:// www.criterios.es/denken/articulos/ denken40.pdf

Quintero, A. (2002). Salsa, identidad y globalización. Redefiniciones caribeñas a las geografías y al tiempo. Trans. Revista Transcultural de Música, $\mathrm{n}^{\circ} 6$, junio. Barcelona, España. Recuperado el 01 de agosto de 2017 de: http://www.redalyc.org/articulo. oa? id=82200609

\section{Lista de fotografías}

$1-2-5$ fueron aportadas por parte de $\mathrm{Xi}$ mena Madrigal Salazar

3- 4 fueron aportadas por parte de Andrea Mora Zamora

6 - Fue aportada por Allan Núñez Rosales

7 - Fue aportada por Douglas Molina.

8 - 9 Fue aportada por Stephanie Araya Jiménez

10 - Fue aportada por María Vanessa Conejo Chaves. 